\title{
O PERFIL DO MERCADO DE TRABA- LHO FORMAL DO ESTADO DO PARANÁ: ANÁLISE DO PERÍODO 1989-1999
}

Laércio Rodrigues de Oliveira*

SUMÁRIO: l.Introdução. 2. As migrações, a região metropolitana e as alteracóes no mercado de trabatho formal. 3. A urbanizaça, o crescimento das grandes cidades e a estrutura do mercado de trabalho formal do Paraná, a partir final dos anos 80.4 . A evolucia da escolaridade no mercado formal paranaense na década de 90. 5. As Influências da Utbanizaça no Mercado de Trabalho e no Perfl do Trabahador. 6.Condusão. 7.Biblografia.

SUMMARY: 1. Introduction. 2. The migrations, the region metropolitan and the alterations in the fomal market of work. 3 . The urbanization, the growth of the big cities and the structure of the formal market of work on Parana, in the end of the years 80 . 4. The evolution from the schooling in the formal Parana's market in the decade of 90.5 . The Influences from the Urbanization in the Market of Work and in the Worker. 6. Final considerations and Conclusion. 7. Bibliography.

SUMARIO: 1. Introducción. 2. Las migraciones, la región metropolitana y las modificaciones en el mercado formal del trabajo. 3. La urbanización, el crecimiento de las ciudades grandes y el estructura del mercado formal del trabajo en Paraná, en el final de los años 80. 4. La evolución de la escuela en el mercado formal del Paraná en la década de 90. 5.Las Influencias de la Urbanización en el Mercado del Trabajo y en el Trabajador. 6. Conclusion. 7. Bibliografia.

RESUMO: A finalidade do presente trabalho é proporcionar uma visâo sobre O Perfil do Mercado de Trabalho Formal do Estado do Estado no Paraná no periodo de 1989-1999. Inicialmente apresenta-se a análise sobre as recentes migrações e a urbanização no Estado e a influência dessa transiçăo populacional no mercado de trabalho. En seguida procura-se analisar o

* Mestre em Economia Politica pela PUC/SP. Professor do Departamento de Economia da Universidade Estadual de Londrina. E-mail laercióul br 
mercado de trabalho após a abertura comercial e o perfil dos trabalhadores regidos pela CIT na decada de 90. Por fim as recomendacós dispostas nas conclusós.

ABSTRACT: The purpose of the present work is to provide a global optics about The Profile of the Formal Market of Work on Paraná State: analysis of the period of 1989-1999. In a first moment it analysis about the recent migrations and the urbanization in the State of Parana and the influence of that transition of people. The study tries to demonstrate the profle of the Parana's job market formal in the decade of 90 . Finally, the recommendations in the conclusions.

RESUMEN: El propósto del presente trabajo es proporcionar una óptica global sobre El perfil del Mercado Formal de Trabajo en el Estado del Paraná el análisis del período de 1989-1999. En un primero momento estudia las migraciones recientes y la urbanización en el Estado del Paraná y la influencra de la transición de personas. El estudio demuestra el perfil del mercado del trabajo del Paraná en la decada de 90 . Finalmente, las recomendaciones en las conchusiones.

PALAVRAS CHAVE: Globalizaçâ. Emprego Migração. Utb̆anizaço.

KEYWORDS: Globalization. Employment Migration. Urbanization.

PALABRAS LLAVE: Globalización. Empleo. Mignación. Urbanización.

\section{Introdução}

O novo milênio se depara com a intensa revolução no sistema de produção e transformações na economia que se avolumam com o decorrer dos dias. Muitas das transformações são motivadas pelo processo de globalização, considerado um dos maiores fenômenos da economia e da política na atualidade. Essas transformações trouxeram intensas mudanças na estrutura da sociedade principalmente na área econômica tanto no âmbito nacional quanto no internacional. As inovaçôes tecnológicas e as transformações ocorridas no sistema produtivo com o surgimento de novos paradigmas deram novo perfil ao mercado de trabalho formal do mundo inteiro com reflexos diretos nos países em desenvolvimentos. 
Para análise destas transformações deve-se levar em consideração as mudanças que ocorreram no relacionamento entre o capital e o trabatho e as variáveis que influenciaram as modificações dos processos de produção. Estas modificaçôes se caracterizaram nas várias fases da Revolução Industrial com a deflagração de diversas questões sociais e o surgimento de medidas protecionistas aos trabalhadores, como resultam do de suas ações e reivindicações.

Os avanços da participação dos trabalhadores na luta e consolidação dos ganhos sociais, veio ocorrer marcadamente nas décadas de 40 e 60 , situação que perdurou até os anos 70 do Século XX. Havia no período, grande desenvolvimento econômico sobretudo nos paises da Europa em razão do Estado Bem-Estar Social (Walfare State), que investia de forma crescente nos beneficios sociais e no modelo fordista de produção baseado na demanda agregada crescente.

Todavia, a crise econômica iniciada na década de 70, aliada aos progressos tecnológicos, modificaram com profundidade os processos de produção, impondo a mundialização da economia. Essas mudanças ocorreram de formas diferenciadas de país para pais, sendo mais penalizados aqueles que estavatn em processo de desenvolvimento, cuja situação foi agravada pelas inseguranças dos mercados financeiros, pelo grande crescimento demográfico, pelas dificuldades de competição nos mercados globalizados, os distanciamento tecnológico e os baixos indices de escolarização dentre outros. Como efeitos perversos dessas mudanças, no âmbito das relações de trabalho, Beltran (1998:76) enumera o aumento no número de desempregados, o desenvolvimento do trabalho informal e do subemprego, o incremento de inúmeras formas precárias de contratação e o arrocho salarial projetando-se sobretudo em modificações normativas e em debates sobre a desregulamentação e as diferentes formas de flexibilização e de terceirização do trabalho.

Neste contexto o objetivo desta pesquisa é trazer para o debate as mudanças ocorridas no mercado de trabalho formal paranaense na década de 90 tendo como base os dados do período entre 1989 e 1999. Pretende-se, também, analisar como as migraçōes influenciaram a formação das grandes concentrações urbanas paranaense e quais foram seus reflexos em épocas recentes.

Optou-se pela análise do mercado de trabalho formal regido pela Consolidação das Leis Trabalhistas - CLT pelo fato de que as relações 
entre o capital e o trabalho no sistema produtivo privado ser mais vulneráveis às variáveis externas. O regime estatutário, outro tipo de contrato formal existente no sistema brasileiro, pelas suas características de estabilidade legal não sofre influência direta da globalização, portanto não será objeto deste estudo. Buscou-se, também, analisar os deslocamentos da população como indicador de causa dos desequilíbrio entre a oferta e a procura de mão de obra no mercado de trabalho formal.

$O$ estudo foi elaborado a partir de dados sobre a população, PIB e mercado de trabalho fornecidos pelo IBGE, IPARDES, IPEA e Ministério do Trabalho e Emprego.

\section{As migrações, a região metropolitana e as alterações no mercado de trabalho formal}

Um dos aspecto a considerar refere-se ao fato de que as migrações paranaenses recentes vieram ocorrer em um período em que o mercado de trabalho urbano estava passando por reestruturação e modernização em razão das mudanças de paradigmas no setor produtivo. No caso brasileiro, o debate sobre os novos paradigmas e flexibilização das relações entre o capital e o trabalho se acentuaram a partir da abertura da economia ao mercado mundial. A abertura econômica veio expor as empresas nacionais à competição internacional cenário onde as formas de produção já haviam, desde o final da década de 70 , incorporado um novo modelo de produtivo que pela sua alta competitividade flexibilidade colocava "Xeque" o modelo fordista.

O modelo fordista, que teve grande sucesso nos países desenvolvidos até início da década de 70 , baseava-se no crescimento sustentado pela demanda agregada com o pleno emprego, aumentos salariais acompanhando o aumento da produtividade e aumento de preços moderados. Todavia as mudança nos rumo da economia européia, a partir dos anos 70 foi apontada como indicativo de esgotamento do modelo fordista e veio ocorrer em meio a uma profunda desordem da economia mundial. Rompia-se o padrão monetário estabelecido na reunião de Bretton woods, baseado no padrão ouro e na taxa de câmbio rígida, elevou-se os preços da matéria prima, principalmente petróleo, e acelerou-se a inflação.

Como conseqüência destas mudanças, intensificou-se a competição entre as principais potências econômicas e neste particular destacou-se a reação da 
economia japonesa em razão dos grandes déficit de sua balança de pagamento. (Tavares e Fiori, 1997:27-53) O Japão promoveu intensa reestruturação industrial utilizando-se da microeletrônica para intensificar a automação com vista ao aumento da produtividade resultando na proposta de um novo paradigma nas relações entre o capital e o trabalho.

Estes avanços no setor produtivo, deram ao Japão melhores condições na competição por novos mercados de bens de consumo em todo o mundo obrigando aos demais países a seguir os mesmos caminhos na reestruturação dos seus sistemas de produção.

Neste cenário é que veio ocorrer a abertura comercial brasileira provocando profundas alterações no mercado de trabalho no início da década de 90. A retrações nas contratações de trabalhadores no mercado formal se acentuaram principalmente após processo de globalização com a liberação do mercado de consumo de bens finais. Além das influências do processo de globalização, um outro indicador aponta que o percentual trabalhadores com contrato assinado no Brasil é relativamente pequeno em relação à População Economicamente Ativa o que caracteriza o alto grau de informalidade. No caso específico do Paraná, ao final da década de 90 apenas 31,43 \% da População Economicamente Ativa (PEA) tinham contratos de trabalho. $\mathrm{Na}$ França o número de trabalhadores com contrato de trabalho ultrapassam $80 \%$ da PEA. (Castel, 1998:145).

Um outro dado a ser considerado, trata-se da facilidade com que os trabalhadores brasileiros são contratados e dispensados ao longo de suas atividades profissionais e que permite não somente a freqüente substituição dos mesmos, como também a adaptação do quadro de pessoal das empresas às crises de mercado de consumo. No caso específico do Paraná, na década de 90, a média anual de desligamentos do trabalho sem justa causa foi em torno de $70 \%$ do total dos trabalhadores do mercado formal' ${ }^{1}$. Estes dados, que são oficiais, demonstram a existência de grande rotatividade que com a globalização dos mercados consumidores podem provocar mudanças no perfil do mercado de trabalho.

Todavia nas décadas anteriores aos anos 90, o mercado de trabalho do Paraná possuía características totalmente diferentes do atual com predomínio das atividades rurais, visto que a população não urbana representavam $63,86 \%$ da população do Estado. No entanto, o fim das fronteiras

Dados fornecidos pelo Ministério do Trabalho e Emprego através do CAGED - Cadastro Geral de Emprego c Desemprego disponíveis no site www.mtb.gov.br 
agrícolas, a modernização da produção rural e as alterações nas relações entre o trabalho e o capital no campo veio estimular grandes fluxos migratórios em direção às cidades provocando mudanças tanto no aspecto habitacional como no mercado de trabalho. No periodo entre 1970 e 1980, realizou-se no Estado do Paraná um dos maiores processos de migração rural da história recente alterando completamente a distribuição populacional. (cf.Zaparolli, 1985: 45)

Os anos que se sucederam deram novos rumos aos movimentos $\mathrm{mi}$ gratórios do Estado com a população, que havia migrado nas décadas anteriores, para as pequenas cidades passaram a migrar novamente, desta vez, em díreção às cidades maiores provocando o esvaziamento de algumas áreas e o surgimento de grandes concentrações urbanas. Este fenômeno pode ser confirmado pelos dados censitários do IBGE sobre o Paraná, desde 1940 até o mais recente realizados em 2000. (tabela 1)

A população do Estado veio sofrendo contínua reorganização espacial desde a década de 40 . Na década de 40 , por exemplo, $74,84 \%$ da população paranaense residia em pequenos municípios com até 50.000 habitantes onde eram desenvolvidas atividades produtivas com características rurais, artesanato, pequeno comércio e poucas indústrias de transformação. Estes números se modificaram, nos censos seguintes, com os pequenos municípios passando a abrigar um número cada vez menor da população. Sucessivamente a população dos pequenos municípios cairiam para 67,76\% em 1950, passando para 62,51\% em 1970, em 1980 para $53,72 \%$, chegando a $47.13 \%$ no ano 2000 . Por estes dados, percebe-se que a partir da década de 70 , o crescimento demográfico foi significativo nas populações das médias e grandes cidades, colocando em evidência um novo rumo ao fluxo migratório.

Tabela 1. Evolução da população urbana e rural no Paraná em comparação com a do Brasil. $1940-2000$

\footnotetext{
${ }^{2}$ No final dos anos 60 , a legislação do trabahlhador rumal sofreu alteraçöes com a exigência do contrato formal. Este fato aliado à expansäo do cultivo da soja provocou mudança na concentraçăo do capital produtivo no campo. 


\begin{tabular}{|c|c|c|c|c|c|c|c|c|}
\hline \multirow{3}{*}{ ANO } & \multicolumn{4}{|l|}{ BRASLL } & \multicolumn{4}{|l|}{ PARANA } \\
\hline & \multicolumn{2}{|c|}{ Populaçào Urbana } & \multicolumn{2}{|c|}{ Populaça Rural } & \multicolumn{2}{|c|}{ Populacão Lrbana } & \multicolumn{2}{|c|}{ Populaça Rural } \\
\hline & Freguentia & Crese. & Freqütencia & $\begin{array}{l}\text { Cresce. } \\
y_{t}\end{array}$ & Frequencita & Crese: & Freguencia & $\begin{array}{l}\text { Crest: } \\
0 \%\end{array}$ \\
\hline 1640 & $1288012 x$ & & 28356133 & & 302772 & & 934004 & \\
\hline 1930 & 98782891 & & & & 528288 & 74,8 & & \\
\hline 1960 & 3153368 & 67.9 & & 16,6 & & 140,1 & & 86,0 \\
\hline 1970 & 52084984 & 65.2 & 4054053 & 6,2 & 2504378 & $91 ., 3$ & 4425400 & 49.9 \\
\hline 9080 & 80437327 & 54,4 & $385+7 y_{3}$ & $-6,0$ & 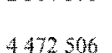 & $7 \$, 6$ & 3157343 & $-2 \Omega 0$ \\
\hline 1001 & 110875826 & & 3604163 & $.6,5$ & $6102 \times 76$ & & 2250323 & -28.8 \\
\hline 2600 & $13: 0 \times 3167$ & 11,01 & 33907406 & $.5,67$ & 7011904 & 13,23 & 1991814 & -11.91 \\
\hline
\end{tabular}

Fonte: Censos Demognanicos de 1940/2000 lBCE

É interessante salientar que do início da década de 40 até ao final da década de 60 , a migração se caracterizava pelo êxodo rural, denominada de migração rural-urbana. Após esse período e por todas décadas seguintes, a migração procedeu das pequenas cidades em direção às cidades maiores, caracterizada de migração urbana-urbana, acentuando-se, a partir de então, o processo de metropolização do Estado.

A metropolização e polarização da população em poucos municípios paranaenses são evidenciadas comparando-se o censo de 1991 com os dados do censo de 2000. Pelo último censo ficou constatando que o Estado tinha 9 milhões de habitantes dos quais cerca de 3.280 .114 habitantes, ou seja, $38,85 \%$ da população estão concentrados em apenas 12 municípios. Pode-se notar que a distribuição da população do Estado entre as regiões foi bastante diferenciada com preferência em favor da Região Metropolitana de Curitiba que conta atualmente com mais de 26,97\% da população do Paraná. (tabela 2)

Tabela 2. Participação da Região Metropolitana de Curitiba na população total do Estado período de 1991 a 2000.

\begin{tabular}{l|l|l|l|l}
\hline Populacho & 1991 & $\%$ & 2000 & $\%$ \\
\hline RMC & 2.057 .578 & 24.37 & 2.425 .361 & 26,97 \\
Outras & 6.385 .721 & 75,63 & 6.578 .443 & 73,06 \\
\hline Total & 8.443 .299 & 100 & 9.003 .804 & 100 \\
\hline
\end{tabular}

Fonte: Censos do $1 B G E$ de 1991 e 2000

Outras regiões, como por exemplo a Extremo Oeste, tiveram sua participação praticamente estável com $17,30 \%, 19,42 \%$ e $17,72 \%$, enquanto que a Paraná Tradicional teve acréscimo em sua participação de 17,57 $\%$ para $20,41 \%$ e $21,07 \%$ nos períodos citados. A Região Norte foi a que 
mais sofreu perdas relativas no período tendo sua participação diminuída de $53.28 \%$ em 1970/80, para $41.29 \%$ em 1980/1991 e $37.73 \% \mathrm{em}$ $1991 / 2000$. Por outro lado, o percentual de urbanização é mais acentuado em alguns municípios, como é o caso de Curitiba, com um grau 100 \% de urbanização e outros como Londrina, Maringá e Ponta Grossa com índice de urbanização superior a $90 \%$ da população residente.

Nos anos 90, a região metropolitana de Curitiba e as maiores cidades do interior foram as únicas que continuaram recebendo contigentes de migrantes regionais. Segundo dados do Instituto Paranaense de Desenvolvimento Econômico Social ${ }^{3}$ (IPARDES), as cidades de Londrina e Maringá receberam $51,32 \%$ de migrantes oriundos de outras regiões do Estado, enquanto que a Região Metropolitana de Curitiba 91,42\% de seus migrantes foram procedentes do interior do Estado. Estes deslocamentos vêm causando desequilíbrio entre a oferta de emprego e as pessoas desempregadas, principalmente em razão das dificuldades das regiōes receptoras em absorver os contingentes adicionais de população, dada a velocidade com que se processa estes deslocamentos.

$O$ volumes dos investimentos que vêm sendo aplicado ao longo da década de 90 na Região Metropolitana de Curitiba e nas principais cidades paranaenses podem ser uma das causas da concentração urbana ocorrida no período em estudo. Segundo dados da Secretaria de Estado da Fazenda do Paraná indicam a acumulação de mais de U\$ 29 bilhōes de dólares em investimentos industriais privados e obras de infraestruturas no período entre 1995 e 1999 . Estes valores correspondem a $8 \%$ dos investimentos brasileiros e o Paraná é a segunda maior carteira de investimentos do país, perdendo apenas para São Paulo, que detém $20 \%$ dos investimentos do Brasil.

Os resultados destes e outros investimentos que vêm sendo realizados ao longo das décadas de 70,80 e 90 , explicam a concentração das atividades econômicas na RMC, principalmente na cidade de Curitiba .(cf.,tabela 3).

\footnotetext{
Os dados sobre as migraçōes paranaenses foram coletados na homepage http//www.ipardes.gov.br em agosto de 2001 . 
Tabela 03 - Produto Interno Bruto - US\$ - valores de 1998

\begin{tabular}{|l|l|l|l|l|l|l|}
\hline Ano & Curitiba & $\%$ & $\begin{array}{l}\text { Outras cidades do } \\
\text { Paraná }\end{array}$ & & $\begin{array}{l}\text { Total do Estado do } \\
\text { Paraná }\end{array}$ \\
\hline 1980 & 8.181 .385 .956 & 23.01 & 27.369 .216 .387 & 76.99 & 35.550 .602 .343 \\
\hline 1985 & 9.767 .308 .948 & 25.61 & 28.376 .011 .744 & 74,39 & 38.143 .319 .203 \\
\hline 1990 & 12.074 .955 .215 & 29.95 & 28.240 .868 .174 & 70.05 & 40.315 .824 .389 \\
\hline 1996 & 14.393 .618 .954 & 31.24 & 31.678 .853 .760 & & 68.76 & 46.072 .471 .714 \\
\hline
\end{tabular}

Fonte: PIB Municipais - IPEA - 200]

Percebe-se pelos dados da tabela 3 que no período entre 1980 a 1996 a cidade de Curitiba teve sua participação no PIB do Paraná aumentada de $23,01 \%$ para $31,24 \%$. Um outro aspecto a considerar é que no mesmo período enquanto o PIB do Estado do Paraná teve um crescimento de $27,50 \%$ o PIB da cidade de Curitiba teve um crescimento de 75,93\% o que explica a concentração das atividades produtiva na Região Metropolitana e especialmente na capital conforme demonstrado pelos dados da Coordenação da Região Metropolitana de Curitiba - COMEC e da Secretaria da Fazenda do Estado do Paraná - SEFA4 4 .

Nota-se, porém , que apesar dos esforços na atração dos investimentos, esses não têm sido capazes, de gerar emprego formal em número suficiente para atender a oferta de mão de obra no mercado de trabalho que constantemente tem migrado das pequenas para as grandes cidades do Estado. A taxa de crescimento da população e os movimentos migratórios aliados às características do novo modelo de produção são fatores que vêm dificultando o equilíbrio entre o número de desempregados e a oferta de emprego para a população urbana.

Embora, a velocidade das taxas de crescimento demográfico, a partir da década de 70, tenha regredido, os desequilíbrio entre a PEA e o nível de oferta de emprego permaneceram altos em favor do desemprego. Nos anos 80, houve redução nas taxas de crescimento vegetativo da população, tendência em se manteve nos anos 90, sendo mais acentuada na área rural, pelas razões que variaram desde os aspectos culturais até as dificuldades para garantia de uma sobrevivência em razão do modelo de produção adotado 5 .

Pelos dados citados, pode-se afirmar que ocorreu a partir do anos 70 o processo de migração acelerada que mudou o perfil do Estado do Paraná

\footnotetext{
* Segundo os dados SEFA e da COMEC a RMC, com 25 municípios, possuía no ano de 2000 27\% dos habitantes do Paraná, 22,1\% da População Economicamente Ativa do Estado e 36,73\% do PIB.

${ }^{5}$ A partir da década 60 adotou-se o registro dos trabalhadores rurais com todos os direitos trabalhistas em razão destas medidas e da modernização dos meios de produção a maioria dos trabalhadores rurais passaram a residir nas cidades.
} 
e influenciou a formação de um novo mercado de trabalho. Um enorme contingente de pessoas em idade economicamente ativa passou a buscar nas atividades urbanas o emprego para sua sobrevivência ${ }^{6}$. O emprego urbano se tornou, para a nova sociedade urbanizada, em desafios permanentes, na buscas de soluções, nem sempre possíveis no curto prazo.

\section{A urbanização, o crescimento das grandes cidades e a estrutura} do mercado de trabalho formal do Paraná, a partir final dos anos 80

Ao final da década de 80 , segundo dados do Ministério do Trabalho e do Emprego, a estrutura do mercado de trabalho formal do Paraná era composto de 1.232.158 trabalhadores celetistas. Nele se destacava o setor terciário composto pelo comércio e serviços, como sendo o mais representativo com $64,65 \%$ dos postos de trabalho formais celetistas. O setor secundário composto pela indústria de transformação, construção civil, indústria de extração mineral e serviços industrial de utilidade pública, representava $29,02 \%$, enquanto que o setor primário contava com apenas $2,41 \%$ dos empregos formais e $3,86 \%$ em outros setores não declarados.

Já ao final da década de 90, o Paraná que possuía uma PEA de 4,2 milhões de trabalhadores o mercado de trabalho formal celetista continha 1.328 .394 trabalhadores rurais e urbanos que representavam $31,62 \%$ da PEA. Em 1999, a estrutura do emprego formal celetista passou a possuir a seguinte composição: setor secundário com 26,35\% dos trabalhadores, setor terciário com $67,56 \%$ e o setor primário com $6,03 \%$ do mercado formal (CLT). Apesar do recuo do emprego formal no setor secundário a indústria de transformação teve variação positiva no período entre 1989 e 1999, o mesmo ocorrendo com os setores terciário e primário da economia.

No período citado, as maiores perdas ocorreram no setor público celetista $(-47,23 \%)$ dos empregos, na extração mineral com $(-30,18 \%)$ e na construção civil com $(-13,12 \%)$ dos empregos formais setor agropecuário teve variação positiva de $211,10 \%$ no emprego formal, o mesmo ocorrendo no comércio com $25,78 \%$, e na indústria da transformação com 18,10\% e emprego total cresceu 7,81\%, passando de 1.232.158 trabalhadores em 1989 para $1.328 .394 \mathrm{em} 1999$. (tabela 4) 
Tabela 4.Variação do emprego formal no Estado do Paraná comparação do período 1989 - 1999 (Em percentual)

\begin{tabular}{|c|c|c|c|}
\hline $\begin{array}{l}\text { Setor } \\
\text { Economico }\end{array}$ & $\begin{array}{l}\text { Ano } \\
1989\end{array}$ & $\begin{array}{l}\text { Ano } \\
1999\end{array}$ & $\begin{array}{l}\text { Variaça } \\
\%\end{array}$ \\
\hline Extraça Mineral & 5.791 & 4.043 & $-30,18$ \\
\hline Ind de Transformaçäo & 289.437 & 341.818 & $+18,10$ \\
\hline Serv. De Industria UP & 17.539 & 17.021 & $-2,91$ \\
\hline Construçâo Civil & 79.979 & 69.334 & $-13,12$ \\
\hline Comerco & 214.918 & 270.320 & $+25,78$ \\
\hline Servicos & 390.276 & 459.395 & +17.78 \\
\hline Adm Pública & 170.100 & 89.162 & $-47 \times 23$ \\
\hline Agropecuñia & 23.884 & 74.563 & $+211,19$ \\
\hline Ontros não declarado & 40.234 & 2.738 & -93.19 \\
\hline Total & 1.232 .158 & 1.328 .394 & $+7,81$ \\
\hline
\end{tabular}

Há de se destacar porém, que nesse período, os movimentos no nível de emprego não foram uniformes. Analisando os empregos existentes em 1989 e comparando-os com os de 1999, no período em que ocorreu a abertura do mercado brasileiro ao comércio internacional, o mercado de trabalho do Paraná teve alteraçôes com variação negativa por vários anos. A abertura da economia brasileira para o comércio mundial, implantada pelo Governo Collor, veio com receituário recessivo (redução do nível de demanda interna através do corte no gastos públicos, da elevação da taxa de juros, do corte do crédito e da redução dos salários) e influenciou de forma negativa o nível de emprego formal no Paraná. Analisando-se os dados do Cadastro Geral de Emprego e Desemprego (CAGED) do Ministério do Trabalho e Emprego nos anos de $1990 \mathrm{e}$ 1993 (cf tabela 5 ) houve a redução de $15,50 \%$ dos postos de trabalho no Paraná. A partir de 1993, o emprego formal volta a crescer, mas somente em 1997 consegue atingir os índices de 1989.

No período entre 1993 a 1999 , no setor da indústria de transformação, por exemplo, teve um crescimento de $28,29 \%$, passando de 248.092 para 341.818 trabalhadores ultrapassando em 18,10\% os números de postos de trabalho de 1989. O setor de serviços também conseguiu recuperar os postos de trabalho perdidos no início da década de 90 , atingindo 459.395 postos de trabalhos formais com 38,79\% acima de 1993 e ultrapassando os postos de trabalho existente em $1989 \mathrm{em} 17,78 \%$. setor agropecuário foi o que teve o maior crescimento relativo no período com 211,19\% de novos (cf.,Tabela 5 e 6 ). 
Tabela 5. Variação do Emprego Formal no Paraná por Setores Econômicos

\begin{tabular}{|c|c|c|c|c|c|c|}
\hline \multirow{2}{*}{ Setor } & \multicolumn{5}{|c|}{ Pariodo logs 1999} & \multirow[b]{2}{*}{$\begin{array}{l}\text { YARLCAO } \\
(0) \\
(d)-(c)\end{array}$} \\
\hline & $\begin{array}{l}1989 \\
(a)\end{array}$ & $\begin{array}{l}1993 \\
(b)\end{array}$ & $\begin{array}{l}\text { VARLACAO } \\
(\%) \\
(a) \cdot(b)\end{array}$ & $\begin{array}{l}1993 \\
(c)\end{array}$ & $\begin{array}{l}1999 \\
(1)\end{array}$ & \\
\hline Est. Minetal & 5.791 & 4.691 & $-18,99$ & 4.691 & 4.043 & -13.81 \\
\hline Ind. De Transformaçà & 289.437 & 266,442 & $-7,94$ & 266,442 & 341.818 & $2 k .29$ \\
\hline Setv. De UR & 17.539 & 17.551 & 0,07 & 17.551 & 17.021 & $-3,12$ \\
\hline Const Cinil & 79.979 & 53.329 & 33,32 & 53,320 & 69.334 & 30,01 \\
\hline Comércio & 214918 & 193853 & 14.45 & 183.853 & 270329 & 47.03 \\
\hline Servọos & 390.276 & 330997 & $-15,19$ & 330.997 & 459.395 & 38.79 \\
\hline Adm Piblica & 170.100 & 50.529 & -70.29 & 50.529 & 89.162 & 76,46 \\
\hline Agrtpecuária & 23.884 & 40.011 & 67.52 & 40.011 & 74.563 & 86,36 \\
\hline Outros & 41.234 & 94.315 & 134,42 & 94.315 & 2.738 & $-47+10$ \\
\hline Total & $\begin{array}{l}1.232 .15 \\
8\end{array}$ & 1.041 .718 & -15.46 & 1.041 .718 & 1.328 .394 & 27.52 \\
\hline
\end{tabular}

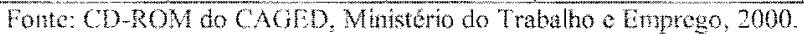

Um outra constatação ocorrida no emprego formal do Paraná é a sua concentração espacial. O número de trabalhadores ao final da década de 90 que estavam no emprego formal celetistas, em Curitiba e nas cidades que compõem a $\mathrm{RMC}$, em relação às demais cidades do interior, é alto ultrapassando a $50 \%$ do total dos trabalhadores do Estado.(tabela 6 )

Tabela 6. Dotribuicăo Lspactal do limprogo lomal (CLT) no Paranta empercentual periodo 1989 a 1999

\begin{tabular}{l|l|l|l|l} 
Ano & RMC & \% & Outras Regioes & $\%$ \\
\hline 1989 & 554.471 & 45.13 & 677.686 & 54.86 \\
\hline 1999 & 691.063 & 52.02 & 637.394 & 47.98
\end{tabular}

Fonte: Ministerio do Trabaho e do Emprego - CAGED, 2000 elaborada pelo autor

Estes números demonstram que durante toda a década de 90 a Região Metropolitana de Curitiba vem mantendo percentuais altos em relação a situação anterior. A RMC com apenas $6,77 \%$ dos municípios do Estado possui mais de $50 \%$ dos trabalhadores do mercado formal celetistas do Estado do Paraná, enquanto que as demais regiões com $93,23 \%$ dos municípios estão perdendo os postos de trabalho formais demonstrando a alta concentração no mercado de trabalho nas cidades próximas à capital do Estado 


\section{A evolução da escolaridade no mercado formal paranaense} na década de 90

Um outro aspecto importante a considerar são as informações sobre a formação escolar dos trabalhadores paranaenses. Considerando-se apenas a década de 90 , constatou-se que no final da década de 80 existiam no mercado de trabalho formal do Estado do Paraná 30.533 trabalhadores celetistas analfabetos, ou seja, $2,33 \%$ do total. Ao final da década de 90 , estes números caíram para 20.682 representando $1,33 \%$ do mercado. $O$ mesmo ocorreu, no mesmo período em relação aos trabalhadores que possúam as séries iniciais do ensino fundamental, que correspondiam $33,81 \%$ do mercado de trabalho em 1989 e tiveram sua participação reduzida para 22,40\% do mercado de trabalho em 1999 (cf. tabela 8)

Tabela 7. Grau de instrução dos trabalhadores do Paraná período $1989 / 99$

\begin{tabular}{|c|c|c|c|c|}
\hline \multirow[b]{2}{*}{ Grau de escolaridade } & \multicolumn{2}{|l|}{1989} & \multicolumn{2}{|l|}{1999} \\
\hline & Qde & $1 \%$ & Qde & {$[\%$} \\
\hline Analfabeto & 30.533 & 2,23 & 20.682 & 1,33 \\
\hline $\begin{array}{l}\text { Ensino Fundamental } \\
\text { Sérics iniciais }\end{array}$ & 463.760 & 33,81 & 349.731 & 22,40 \\
\hline $\begin{array}{l}\text { Ensino Fundamonal } \\
\text { Séries finais }\end{array}$ & 387.568 & 28,26 & 499.568 & 32,02 \\
\hline Ensino médio & 303.972 & 22,16 & 451.46 & 28.94 \\
\hline Superior & 170.187 & $\longdiv { 1 2 , 4 1 }$ & 238.111 & 15.26 \\
\hline Ignonato & 15.459 & 1,13 & 843 & 0,05 \\
\hline Total & & 100 & & 100 \\
\hline
\end{tabular}

Já a participação de trabalhadores com as séries finais do ensino fundamental tiveram aumento de $28,90 \%$ para $32,02 \%$ no período em estudo. Da mesma forma, os trabalhadores com o ensino médio e curso superior tiveram acréscimos em sua participação no mercado de trabatho do Estado, passando de 22,16\% e 12,41\% em 1989 para 28,94\% e $15,26 \%$ em 1999 respectivamente com o acréscimo de $48,52 \%$ e $39,91 \%$ no mesmo período.

Estes dados revelam que os trabalhadores com maior grau de escolaridade estão tendo preferência para contratação e/ou permanência no mercado de trabalho formal, fazendo com que a escolaridade média dos 
trabalhadores se elevem no Estado.

Por outro lado os dados do Ministério do Trabalho e Emprego revelam que a média de escolaridade dos trabalhadores urbanos é de 6,4 anos de estudo 7 e apontam ainda que $60 \%$ da PEA não possuem o primeiro grau. Diante destes dados pode-se levantar um questionamento os trabalhadores do Estado do Paraná têm maior grau de escolaridade do que a média nacional ou os trabalhadores com menor escolaridade estão sendo empurrados para informalidade.

É importante ressaltar também que a escolaridade decresce com a idade. Os jovens e as mulheres possuem em média 7 anos de estudo enquanto que os mais velhos do sexo masculino a media cai para menos de 6 anos. Na zona rural a média de escolaridade cai para 3,2 anos. No Chile e na Argentina a média de escolaridade é de 8 anos dados de 1998.

Deve-se também ressaltar o perfil do trabalhador quanto a sua escolaridade por gênero ${ }^{8}$. No caso do Paraná, tendo como base os dados de 1989 e 1999, indicavam que no ano de 1989 cerca de $73,57 \%$ dos trabalhadores analfabetos eram homens e 26,43 mulheres; já em 1999, os dados indicavam que os homens representavam $69,44 \%$ e as mulheres $30,56 \%$ dos trabalhadores sem escolaridade.

Com ensino fundamental, séries iniciais, os trabalhadores do sexo masculino representavam $77,75 \%$ do mercado de trabalho enquanto que as do sexo feminino eram de apenas $22,25 \%$. Passados 10 anos, ao final da década de 90 , a participação dos trabalhadores homens cairiam 3 pontos percentuais ficando em $74,83 \%$ do mercado e as mulheres $25,17 \%$.

No caso dos trabalhadores com ensino fundamental, séries finais, os homens representavam $70,26 \%$ e as mulheres $29,74 \%$ do mercado de trabalho em 1989. Em 1999 os homens seriam 68,96\%, enquanto as mulheres $31,04 \%$. Já os trabalhadores, do mercado formal, com grau de escolaridade média, em 1989, 54,79\% eram homens e 45,21 mulheres, em 1999 os homens representavam $53,64 \%$ e as mulheres $46,36 \%$. Em relação aos portadores de grau superior de instrução em 1989 os homens seriam $49,49 \%$ do mercado e as mulheres representariam $50,51 \%$ em 1999 os

\footnotetext{
Fstes dados constam das recomendaçóes no documento, Educaçäo Profissional um projeto para o desenvolvimento sustentado elaborado pelo Ministério do Trabalho e Emprego. Brasilia . 1999, p.5 - Dados da RAIS fornecido pelo Ministerio do Trabalho e do Emprego em novembro de 2.000 
trabalhadores com grau superior de escolaridade 44,98\% eram homens e $55,02 \%$ mulheres.

Em termos gerais a composição do mercado de trabalho formal do Estado do Paraná, em 1989, era formado por 66,90\% de trabalhadores do sexo masculino, enquanto que $33,10 \%$ do sexo feminino. Já ao final dos anos 90, isto é em 1999, os homens perderiam 4 pontos percentuais e seriam $62,18 \%$ enquanto que as mulheres $37,82 \%$ do mercado de trabatho

Estes dados revelam que a participação dos trabalhadores do sexo feminino, no Estado do Paraná, vem crescendo à medida que aumenta o grau de escolaridade. Esta participação teve o acréscimo de 29,97\% entre 1989 e 1999, enquanto que a participação do sexo masculino cresceu apenas $5,72 \%$ no mesmo período. A baixa escolaridade vem se tornando o grande diferencial em épocas de globalização.

\section{As Influências da Urbanização no Mercado de Trabalho e no Perfil do Trabalhador}

Na presente pesquisa buscou-se também analisar outros aspectos referente ao mercado de trabalho dentre os quais a distribuição da renda e a influência da urbanização. Para a análise da influência destas variaveis no mercado de trabalho foram utilizados os dados referentes a população total, taxa de urbanização, grau de escolarização, renda e emprego formal das (05) cinco maiores cidades do Estado e comparados com os mesmos dados de (5) cinco cidades menores menos urbanizadas. Os dados foram coletados juntos ao IPARDES, IBGE, Ministério do Trabalho e Emprego. Elegeu-se os municípios de Curitiba, Ponta Grossa, Londrina, Maringá e Cascavel que polarizam suas regiōes e somavam juntos em 1999 cerca de 2.372 .401 habitantes e representavam $28,08 \%$ da população do Estado. Para efeito de comparações, no outro extremo escotheu-se os cinco menores municípios de diferentes regiões do Estado em termos populacionais dentre eles Santo Antonio do Sudoeste, Santa Helena, Ribeirão Claro, Manoel Ribas e Paulo Frontim nos quais a taxa de urbanização na ocasião era inferior a $50 \%$ (cf. tabela 8).

"Em 2001 foi publicado o Censo IBGE que são os iltimos dados oficiais. 
Analisando-se especificamente a cidade de Curitiba consta que possuía 1.476.253 habitantes, ${ }^{10}$ onde cerca de $31,51 \%$ dos trabalhadores recebiam rendas de até dois salários mínimos, $48,7 \%$ tinham até quatro anos de escolaridade e o emprego com carteira assinada atingiam 35,65 $\%$ da população economicamente ativa . Assim como Curitiba, os municípios de Londrina, Maringá, Ponta Grossa e Cascavel que possuíam taxas de urbanização acima de $90 \%$ ficou demonstrado que os trabalhadores tinham maior grau de escolaridade e maiores ganhos salariais $\mathrm{em}$ relação aos menores municípios tais como Santo Antonio do Sudoeste, Santa Helena, Ribeirão Claro, Manoel Ribas e Paulo Frontim onde a taxa de urbanização era inferior a $50 \%$.

Ficou demonstrado também que, nas maiores cidades, os trabalhadores com ganhos até dois salários mínimos representam menos de $50 \%$ da população ocupadas, enquanto que nas cidades menores o índice é superior a $70 \%$ dos trabalhadores ocupados no emprego formal.(tabela 8 )

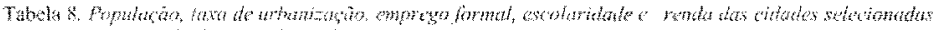

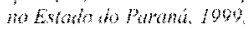

\begin{tabular}{|c|c|c|c|c|c|}
\hline (adates selcointatas & $\begin{array}{l}\text { Populatuta } \\
\text { Tutat }\end{array}$ & 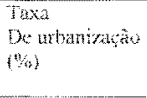 & 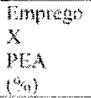 & 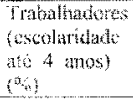 & 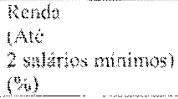 \\
\hline Cutings & $1.476,353$ & 100 & $36,6,5$ & $4 X_{4}$ & 31.54 \\
\hline Iondina & 410,489 & 0,70 & 2482 & 56,9 & 48,73 \\
\hline Haringa & 389.753 & 07.35 & $35 .+7$ & 59.6 & .39 .81 \\
\hline bona forossa & 273,469 & 74,48 & 25.89 & 58.14 & 49.20 \\
\hline Craculet & 245066 & 90,42 & $21,1 \mathrm{~A}$ & 50,58 & 48,7 \\
\hline Ginto sta sulouste & 20.299 & $40+17$ & 19,94 & 69.31 & 77.3 \\
\hline Somtallatera & $\mid M, 401$ & 31,59 & 25,60 & 68.48 & 75.94 \\
\hline Ribenco Cluta & 14,950 & 49.70 & 11,32 & 60.23 & 74.85 \\
\hline Manocl Rithas & $11.95 \mid$ & 37,66 & 15.51 & $6 \varepsilon_{1}, n_{2}^{2}$ & 79,01 \\
\hline Padto STwnlin & 6,58 & 35.28 & 4.8 & 70,42 & 7,302 \\
\hline
\end{tabular}

Com relação à escolaridade, nas cidades maiores o percentual de trabalhadores com menos de quatro anos de estudo é inferior a $60 \%$, enquanto que nas menores cidades o percentual estavam entre 73 e $79 \%$ do total dos ocupados no emprego formal. $\mathrm{O}$ emprego formal em relação à PEA também aumenta à medida que a taxa de urbanização cresce. $O$ que significa que nas cidades menores o grau de informalidade e a precariedade nas relações de trabalho são maiores em relação às grandes cidades. Desta forma, pode-se concluir que a urbanização e o grau de escolaridade, no caso específico do Estado do Paraná, têm influência positiva na distribuição da renda e no emprego formal.

\footnotetext{
37 Estes dados foram junto ao IPARDES - Instituto Paranaense de Desenvolvimento Social www.jpardes.gov.br e ao Ministerio do Trabalho e Emprego www.mtb.gov.br. 
Por outro lado os reflexos desta urbanização acelerada, principalmente as ocorridas nos anos 90 , e a concentração urbana dela decorrente vem provocando a exclusão de grande parte da população. Este fato pode ser comprovado pelo documento n( 14 do IPEA ${ }^{11}$. O documento indica que nos Estados da Região Sul, estão 4.082 .314 de indigentes, sendo que no Paraná se encontravam 1.883 .043 habitantes nessas condições o que representava $46,12 \%$ da Região e $12,44 \%$ dos indigentes do Brasil respectivamente.

\section{Conclusão}

Buscou-se com esta pesquisa analisar as transformações que ocorreram no mercado de trabalho formal do Paraná na década de 90. Pretendeu-se com ela apresentar discussões sobre o perfil do mercado de trabaTho paranaense após as migrações ocorridas a partir dos anos 70 e os reflexos dos investimentos ocorrido no Estado e a globalização da economia brasileira que ocorreu no início dos anos 90 .

A globalização, tal como vem ocorrendo, provocou alterações profundas no sistema produtivo do mundo capitalista com reflexos nas relações econômicas motivadas pelas novas tecnologias que geram aumento da produtividade e alterações nas relações trabalhistas com destaque para a crescente flexibilização e a terceirização do trabalho. A economia mundial, nas últimas décadas, aponta novos rumos com as inovações do comércio internacional, a criação de grandes blocos econômicos e entidades internacionais que favoreceram a implantação e o funcionamento dos meios de regulação das relações comerciais dentre as quais a OMC, com influência sobre o mercado de trabalho.

A globalização tecnológica interferiu no mercado de trabalho à medida que as empresa, em um ambiente competitivo, sofreram reestruturação abandonando o modelo de produção fordista e introduzindo novas formas de produção com a redução de seus quadros de trabalhadores. $O$ uso da tecnologia e seus efeitos sobre o nivel de emprego é tema controvertido em razão de que para alguns países, o seu uso não tem sido fator causador de grandes taxas de desemprego, como é o caso do Estados Unidos, que em 1999 teve a taxa de 5,5\% e o Japão a taxa

10 documento n,14 do IPEA, foi publicado em março de 1993, como subsídio à formulação de uma política de segurança alimentar. A pesquisa foi coordenada por Ana Maria Peliano. 
$3 \%$ de desemprego. No entanto, outros países usaram a tecnologia e experimentaram taxas elevadas de desemprego como é o caso da Alemanha com 9\%, a Dinamarca com 11\%, a França com 12\%, a Bélgica com $14 \%$ e a Espanha com 24\% sendo a mais elevada.

Diante destes dados, pode-se notar que o impacto da tecnologia na economia depende dos arranjos institucionais nas relações entre o capital e o trabalho. Nos Estados Unidos, Japão e Tigres Asiáticos há uma maior flexibilidade nas contratações e na forma de remuneração do trabalho. São países com baixos encargos sociais. $\mathrm{Na}$ Europa, de um modo geral, as leis e contratos continuam muitos rígidos e os encargos sociais relativamente altos e poucos negociáveis.

No entanto, a globalização é positiva como fator difusor do capital produtivo a medida que cria formas de trabalho onde as atividades repetitivas e cansativas passam a ser executadas pelas máquinas aumentando a produtividade, reduzindo os preços possibilitando maior consumo da classe trabalhadora.

Pelos dados apresentados nesta pesquisa constatou-se que nos primeiros anos da década de 90, no Estado do Paraná, foram marcados por profundas alterações no mercado de trabalho. A redução do emprego foi mais acentuada junto aos trabalhadores menos qualificados e veio acompanhada das alterações nas relações entre o trabalho e o capital com formas precárias de contratação e remuneração. A abertura ao comércio internacional, principalmente em razão da modernização dos meios de comunicação, do avanço da informática e da redução das barreiras protecionistas alfandegárias (tarifárias e não tarifărias) deram origem ao fomento do intercâmbio tecnológico e a ampliação dos mercados consumidores provocou a desestruturação da base da produção da indústria nacional influenciando o nivel de emprego.

A partir da globalização, houve maior facilidade de acesso às matérias primas e bens intermediários, maior possibilidade de trocas nas negociaçôes comerciais aumentando desta forma, os beneficios das vantagens comparativas nas economias de escala. A competição globalizada passou a exigir constante atualização nos modelos de produção com a implantação de técnicas modernas e as alterações nas relações entre o capital e o trabalho, com reflexos no nível de emprego nos setores mais dinâmicos onde as novas tecnologias foram implantadas. 
A entrada de produtos estrangeiros, com preços mais competitivos, alterou o perfil do mercado consumidor, com conseqüências imediatas no mercado de trabalho. Desta forma, como conseqüências, houve nos primeiros anos da década de 90 , a redução do emprego formal celetistas e o aumento das formas precárias de contratação no mercado de trabatho - autônomos, terceirizados e empregos domésticos.

Os efeitos negativos da abertura comercial sobre o mercado de trabalho, foram mais acentuados nos quatro anos iniciais da década de 90 . No período entre final de 1989 e o final de 1993 o Paraná perdeu 15,46\% dos postos de trabalho formais que somente foram recuperados ao final da década de 90 . Todavia a recuperação dos postos de trabalho na segunda metade do período não ocorreu em todos os setores e o perfil dos trabalhadores ocupados também são diferentes aos do início da década pesquisada. Um outro dado revela que o emprego com carteira assinada no Paraná corresponde a cerca de $31,47 \%$ da PEA do Estado, sendo que mais de $50 \%$ desse total estão localizados na Região Metropolitana de Curitiba, demonstrando-se desta forma, o alto grau de concentração do mercado de trabalho.

A pesar dos esforços oficiais na atração de investimentos produtivos, esses não têm sido capazes, de gerar emprego em número suficiente para atender a oferta de mão de obra no mercado formal de trabalho do Estado. A taxa de crescimento da população e os movimentos migratórios aliados às características do novo modelo de produção são fatores que vêm dificultando o equilíbrio entre os que buscam trabalho e a oferta de emprego no mercado formal. As ofertas de emprego celetistas na década de 90 foram bem inferiores ao crescimento da população urbana.

Nota-se que os problemas do mercado de trabalho tem, cada vez mais, se tornado importante na agenda dos debates nacionais. Todavia, percebe-se que na maioria das vezes, essa questão tem sido tratada de maneira restrita às variáveis tradicionalmente internas ao mercado de trabalho dentre as quais a qualificação do trabalhador, como sendo a causa central da situação desfavorável de desemprego. Ocorre, todavia, que as causas principais do desemprego são mais abrangentes, envolvendo variáveis estruturais, como as mudanças de paradigmas tecnológico-produtivos, a incapacidade dos Estados realizarem políticas sociais duradouras, políticas econômicas de curto prazo sem compromissos com pleno 
emprego, distribuição de renda inadequada e a intensificação da internacionalização da economia em um ambiente de desregulamentação e de aprofundamento da concorrência.

Conclui-se, então, que a questão do emprego no Paraná, deve passar por ações que estejam incorporadas a um projeto mais amplo de desenvolvimento sustentado da economia com políticas que no curto prazo visem o crescimento das atividades que utilizem maior número de trabalhadores. A longo prazo sugere-se que as politicas de apoio ao trabalhador desempregado se desenvolvam de forma uniforme em todo Estado, articulada com o mercado de trabalho, visando desta forma incorpora-lo aos novos paradigmas produtivos. Sugere-se também um modelo institucional da política de emprego que estimule o emprego duradouro na iniciativa privada com a revisão da legislação tributária e dos encargos sociais incidentes nos contratos de trabalho formal.

Para implementação destas ações tem-se a necessidade de mobilizar a poupança interna em direção do setor produtivo, desestimulando aplicações especulativas; utilizar-se dos bancos oficiais de fomento para estimular as atividades com maior utilização de mão de obra; estímular a reestruturação produtiva das empresas públicas e privadas visando a competitividade nacional e internacional; investir em infraestrutura básica visando aumentar as vantagens comparativas em relação a outros Estados mais desenvolvidos; manter e ampliar o programa de reforma agrária buscando a reintegração dos trabalhadores rurais visando diminuir a pressão no mercado de trabalho urbano das grandes cidades e desenvolver a qualificação do trabalhador articulada com o ensino formal e com as necessidades do mercado de trabalho atual.

\section{BIBLIOGRAFIA}

BARRAL, Welber. O Brasil e a OMC: Os interesses brasileiros e as futuras negociações multilaterais, Florianópolis, Diploma Legal, 2000.

CACCIAMALI, Maria Cristina. A Globalização e suas Relações com o Mercado de Trabalho, Cadernos da PUC, 1997.

CASTEL, Robert. As metamorfose do trabalho in globalização: o fato e o mito organização: José Luis Fiori, Marta Skinner de Lourenço, José Carvatho de Noronha, Rio de Janeiro, Ed. UERJ,1998.

COUTINHO \& FERRAZ. Estudo da Competitividade da Indústria Brasi- 
leira. $2^{\circ}$ edição. Campinas. SOBEET, 1994.

CORSI, F. L. A Globalização e as Crise do Estados Nacionais. in Desafios da Globalização/org. Ladislau Dowbor, Otávio Ianni, Paulo-Edgar A. Rezende - Petrópolis, RJ: Vozes, 1997

DINIZ, Bismarck Duarte. Organização Sindical Brasileira: Uma Abordagem crítica para uma construção do Mercosul. IX Encuentro Internacional de Derecho de América del Sur, La Paz, Bolívia, Out/2000.

DOWBOR, L.; IANNI, O; RESENDE, P. (orgs). Desafios da globalização. Petrópolis (RJ). Vozes, 1997

DUPAS, Gilberto. A Lógica da Economia Global e a Exclusão Social. Síntese da Pesquisa. Estudos Avançados n. 34, IPA/USP, 1999.

ENGUITA, Mariano F. Trabalho, escola e Ideologia. Porto Alegre: Artes Médicas Sul, 1993.

GORENDER, Jacob. Globalização, Mudanças Tecnologicas e Novos Processos de Trabalho e Produção. In Globalização, Regionalismo e Nacionalismo. Flávia M. de Oliveira (org.) SP, Editora UNESP, 1999.

HIRATA, Helena. Da polarização das qualificações ao modelo da competência. In: FERRETTI, Celso J. (coord.) Novas tecnologias, trabalho e educação: um debate. INOVA: gestão e tecnologia. São Paulo, PGT/USP, n.13 e 14 jan./abr., maio/ago.1997.

IPARDES - Instituto Paranaense de Desenvolvimento Econômico. Governo do Paraná, 2001.

IBGE - Instituto Brasileiro de Geografia e Estatística. Rio de Janeiro - 2001. KONZEN, Otto Guilherme; ZAPPAROLI, Irene Domenes. Estrutura Agrária e Capitalização da Agricultura no Paraná. Revista de Economia e Sociologia Rural, Brasília, v.28, n.4, p.155-173, out./dez. 1990.

LEITE, Marcia de Paula. Qualificação reestruturada e os desafios da formação profissional Cadernos de Pesquisa. N. 11. P. 79-96. Jan./jun. 1995.

KAWAMURA, Lili. Qualificação do Trabalho face as novas tecnologias: parâmetros culturais. Campinas, Cadernos TTEduc, Faculdade de Educação, Unicamp, 1993.

MARX, Karl. O capital : Crítica a Economia Política. São Paulo: Nova Cultural, 1985.

MATTOSO, Jorge. A desordem do trabalho. São Paulo: Scritta, 1995.

Mtb (2000) Cadastro Geral de Emprego e Desemprego (CAGED) Ministério do Trabalho e Emprego. Brasilia, 2000.

PASTORE, José. Flexibilização dos mercados de trabalho e contratação coletiva. São Paulo, LTR, 1998

POCHAMANN, Márcio. Política do Trabalho e Garantia de Renda no Capitalismo em Mudança, SP, LTR, 1995.

RIBEIRO, Maria de Fátima . O Euro e as Perspctivas de Implantação de uma Moeda Única no Mercosul. Revista de Direito Constitucional e Inter- 
nacional. SP, RT, n.31, ano 8, abril-junho de 2000.

RIBEIRO, Maria de Fátima. O Preço de Transferência (Transfer Pricing) in Anais do IX Encuentro Internacional de Derecho de America del Sur. La Paz, Bolivia, outubro de 2000.

RIFKIN, Jeremy. O fim dos empregos. São Paulo. Makron Books, 1995

TAVARES, M. C. Mitos globais e fatos regionais: a nova desordem internacional. in Globalização: o fato e o mito/José Luis Fiori (org.) Rio de Janeiro, EduER], 1998

ZAPAROLLI, Irene D. A Evolução da Estrutura Agrária no Estado do Paraná. Dissertação de Mestrado em Economia Rural, UFRS, 1985 